\title{
Essential drugs in diabetes: South and South East Asian perspective
}

\author{
Sanjay Kalra, Yashdeep Gupta ${ }^{1}$, Banshi Saboo ${ }^{2}$ \\ Department of Endocrinology, Bharti Hospital and B.R.I.D.E, Karnal, Haryana, Departments of Medicine, ${ }^{1}$ Government Medical College, \\ Chandigarh, ${ }^{2}$ Ahmedabad, Gujarat, India
}

\section{INTRODUCTION}

The National List of Essential Medicines (NLEMs) is not only a guide for rational prescription, but also a barometer of a country's health priorities, whereas most NLEMs are similar to the World Health Organization (WHO) list, each country's list has additions, deletions and modification, which reflect its unique health related challenges. ${ }^{[1-13]}$

The South East Asia region (SEARO) of the WHO, along with neighboring South Asian world's countries of Afghanistan and Pakistan, is home to some of the world's, largest populations. This region also plays unwilling host to the diabetes pandemic: Almost all of its countries care for significant number of people living with diabetes.

In such a situation, it becomes necessary to study the NLEMs of these nations, to assess if adequate provision has been made for essential antidiabetic drugs. An online search was performed to identify the latest NLEMs of the 11 SEARO countries. These are Bangladesh, Bhutan, Democratic People's Republic of Korea (DPRK), India, Indonesia, Maldives, Myanmar, Nepal, Sri Lanka, Thailand and Timor Leste. Two geographically contiguous member countries of the South Asian Association for Regional Cooperation (SAARC), viz. Afghanistan and Pakistan, were also included in the search.

\begin{tabular}{|l|l|}
\hline \multicolumn{2}{|c|}{ Access this article online } \\
\hline Quick Response Code: & Website: \\
\hline & www.joshd.net \\
\hline & \\
\hline
\end{tabular}

National List of Essential Medicines were available for all states except DPRK, for which the WHO has issued a list of life-saving drugs to guide potential donors.

The antidiabetic drugs listed each NLEM were analyzed according to class of drugs, and strengths. Various NLEMs were compared with assess similarities and contrasts.

\section{SeCRETAgogues}

All countries (with the exception of DPRK) mention glibenclamide as an essential drug, specifying both $2.5 \mathrm{mg}$ and $5 \mathrm{mg}$ strengths. Some countries such as Afghanistan, Bhutan, Myanmar, and Sri Lanka include only the $5 \mathrm{mg}$ tablet in the NLEM.

Recently, the WHO restricted use of glibenclamide in persons aged $>60$ years, because of the risk of hypoglycemia. ${ }^{[14]}$ In view of this, most SEARO/SAARC countries have included newer generation sulfonylurea in their NLEMs. Myanmar is the only country with three modern sulfonylureas, viz. glipizide $(5 \mathrm{mg})$, gliclazide (80 mg) and glimeperide (1, $2 \mathrm{mg})$ in its NLEM. Thailand lists glimepiride (strength not specified), gliclazide $(80 \mathrm{mg}$ ) and a meglitinide secretagogue (repaglinide 0.5, 1, $2 \mathrm{mg}$ ) in the NLEM. Maldieves includes gliclazide $80 \mathrm{mg}$ in its NLEM. Nepal lists glipizide $(2.5,5 \mathrm{mg})$, while Indonesia includes its $5 \mathrm{mg}$ strength Afghanistan, Bhutan India, Nepal, and Pakistan do not list any sulfonylurea apart from glibenclamide in their NLEMs.

\section{SENSITIZERS}

Metformin $500 \mathrm{mg}$ is included in the NLEM of all countries. Pioglitazone is another insulin sensitizer, which finds mention in the Bhutanese (15 mg) and Thai (15, $30 \mathrm{mg}$ ) NLEMs. 


\section{ALPHA GLUCOSIDASE INHIBITORS}

The class of Alpha-glucosidase inhibitors is represented in the NLEM of Thailand by acarbose. However, the strength of the molecule is not mentioned. Other classes of oral antidiabetic drugs are not included in any NLEM.

\section{INSULIN}

Insulin is an essential, lifesaving drug, which deserves mention in NLEM. North Korea, however, does not include insulin in its guidance for donors, which lists - life saving drugs that can be provided to the country.

Regular insulin is included in all other NLEMs of the SEARO region and the SAARC countries. Most countries also include intermediate - acting insulin. While some countries specify only isophane (neutral protamine Hagedorn (NPH]) insulin, others continue to list the now discontinued lente/insulin zinc suspension formulation.

An issue which needs to be addressed is that of correct terminology for insulin. Intermediate insulin is described by various names, and this can lead to confusion among health workers. Myanmar, for example, lists both types, while defining "insulin - long-acting insulin zinc suspension (mixed, crystalline)." India, Nepal, and Pakistan include both NPH and Lente, Thailand specifies $\mathrm{NPH}$ alone. Indonesia does not mention particular type of intermediate insulin, while Bangladesh omits this category from its NLEM.

Premixed insulin is included by Bhutan, Sri Lanka, India, Indonesia and Nepal in their essential lists.

Thailand includes selected insulin analogs: Aspart and biphasic lispro (ratio not mentioned) as part of the NLEM. Again, the required strength, delivery devices and needles are not specified

There is considerable variation regarding the concentration of insulin preparation of insulin, Bhutan, India Nepal ask for $40 \mathrm{IU} / \mathrm{ml}$; Bangladesh, Indonesia Myanmar and Sri Lanka for $100 \mathrm{IU} / \mathrm{ml}$, while Thailand does not specify any preference. Afghanistan Maldives and Timor Leste accept both strengths as being essential.

Pakistan presents a unique scenario: Soluble insulin is listed as $100 \mathrm{U} / \mathrm{ml}$ strength, while intermediate insulin is specified in both 40 and $100 \mathrm{U} / \mathrm{ml}$ concentrations.
None of the countries specify insulin syringes an irreplaceable component of the insulin prescription, as being essential.

\section{HYPOGLYCEMIA}

The Indian NLEM devotes a separate section to the management of hypoglycemia, and mentions injection glucagon and 25\% dextrose as essential drugs.

\section{DISCUSSION}

This analytical study of South East Asian and South Asian countries reveals significant findings.

The SEARO region and neighboring SAARC countries are a diverse group of nations, united by the diabetes epidemic. Their choice of antidiabetic drugs in NLEMs exhibits commonalities (e.g., metformin, glibenclamide, regular insulin) as well as differences (other sulfonylureas, pioglitazone acarbose, insulin strength, insulin analogues).

Some of these differences can be explained by local dietary habits (acarbose, repaglinide and aspart for postprandial hyperglycemia in Thailand, for example), local availability (40 IU vs. 100 IU strength of insulin) or prescription habits of physicians. Other dissimilarities, however, cannot be explained so easily.

Metformin is considered an essential drug by all countries, while another sensitizer, pioglitazone, is included in two lists. This assumes significance in view of the recent controversy regarding this molecule in India. ${ }^{[15]}$

Some SEARO countries display a proactive, modern approach to sulfonylurea therapy by including safer, newer generation molecules. This is a welcome trend, as it supports the concepts of safety (minimizing hypoglycemia), addresses the challenge of geriatric diabetes, and allows freedom of choice in prescription.

The Alpha-glucosidase inhibitor acarbose is listed by one SEARO country (Thailand), this inclusion highlights the importance and efficacy of this molecule, especially in this part of the world.

Insulin is included in every NLEM of SEARO/SAARC. However, there is marked heterogenecity in choice of preparations, nomenclature, and insulin concentrations. Insulin analogues are listed by one country (Thailand), but insulin syringes are not specified separately. 
Five countries include premixed insulin as an essential drug. This fact underscores the universal appeal and efficacy of this insulin preparation.

The issue of hypoglycemia is addressed by one nation (India). This is a welcome step, as it highlights the importance of managing this preventable complication in people with diabetes.

\section{CONCLUSION}

Not much attention has been paid by clinicians to NLEMs. In the past concerted action is needed to tackle diabetes, however. This includes ensuring listing and availability of all important antidiabetic drugs in NLEMs. While some authors have analyzed NLEMs in the past, ${ }^{[14,15]}$ these important documents need to be highlighted in mainstream literature.

Best practice sharing between various countries, interdisciplinary discussion between pharmacologists, public health specialists and diabetes care professionals, and indigenous health economics data are required to create robust NLEMs for diabetes.

Regular updation of the diabetes sections of NLEMs is also necessary to keep pace with advances in pharmaceuticals. Newer oral antidiabetic drugs and insulin analogs, with proven safety, should be included in NLEMs, even if for restricted use. This will help these drugs benefit the people who people who need them most.

The NLEMs are an important tool in our crusade against diabetes: We must not under-estimate their importance rather, we should work together to strengthen their utility in this regard, and to promote rational drug use in diabetes care.

\section{REFERENCES}

1. National Essential Drugs List Islamic Republic of Afghanistan. Available from: http://www.apps.who.int/medicinedocs/ documents/s17405e/s17405e.pdf. [Last accessed on 2014 Apr 13].
2. Report on drafting the updated essential drug list. Available from: http://www.209.61.208.233/LinkFiles/Essential_Drugs_and Medicines_BAN.pdf. [Last accessed on 2014 Apr 13].

3. National List of Essential Medicines of Bhutan 2012. Available from: http://www.apps.who.int/medicinedocs/documents/ s17826en/s17826en.pdf. [Last accessed on 2014 Apr 13].

4. National List of Essential Medicines of India 2011. Available from: http://www.mohfw.nic.in/WriteReadData/ I892s/7364497513National\%20 List\%20of\%20Essential\%20 Medicine,\%202011.pdf. [Last accessed on 2014 Apr 13].

5. National List of Essential Medicines Indonesia 2008. Available from: http://www.apps.who.int/medicinedocs/documents/ s18011en/s18011en.pdf. [Last accessed on 2014 Apr 13].

6. Essential Medicines List 2009 Maldives Food and Drug Authority. Available from: http://www.apps.who.int/medicinedocs/documents/ s17044e/s17044e.pdf. [Last accessed on 2014 Apr 13].

7. Essential and Complementary Medicines and Vaccines for Myanmar. National List. (NLEM), 2010. Available from: http:// www.apps.who.int/medicinedocs/documents/s20297en/ s20297en.pdf. [Last accessed on 2014 Apr 13].

8. National List of Essential Medicines of Nepal 2011. Available from: http://www.searo.who.int/entity/medicines/neml_nep_2011_ govtwebsite_ok.pdf. [Last accessed on 2014 Apr 13].

9. National Essential Medicine List of Pakistan. Ministry of Health. Government of Pakistan. Available from: http://www.apps.who.int/ medicinedocs/documents/s17119e/s17119e.pdf. [Last accessed on 2014 Apr 13].

10. National List of Essential Medicines Sri Lanka 2009. Available from: http://www.apps.who.int/medicinedocs/documents/ s16730e/s16730e.pdf. [Last accessed on 2014 Apr 13].

11. Essential Medicines List for Timor Leste 2010. Available from: http://www.apps.who.int/medicinedocs/documents/s19453en/ s19453en.pdf. [Last accessed on 2014 Apr 13].

12. Essential Drugs Suggested to be Used by International Agencies in DPRK. Available from: http://209.61.208.233/LinkFiles/ Essential_Drugs_and_Medicines_DPRK.pdf. [Last accessed on 2014 Apr 13].

13. National List of Essential Medicines 2008 [Thailand]. Available from: http://www.apps.who.int/medicinedocs/documents/ s16245e/s16245e.pdf. [Last accessed on 2014 Apr 13].

14. Kalra S, Bajaj S, Mithal A. Endocrinology and the essential list. Indian J Endocr Metab 2012;16:133-5.

15. Kalra S, Das AK, Chowdhury S, Shah S. Indian Public Health Standards 2012 and the diabetes pharmacopoeia. Indian J Endocr Metab 2013;17:1-3.

How to cite this article: Kalra S, Gupta Y, Saboo B. Essential drugs in diabetes: South and South East Asian perspective. J Soc Health Diabetes 2015;3:4-6.

Source of Support: Nil. Conflict of Interest: None declared. 